\title{
Synthesis of Zinc Oxide Supported on Titanium Dioxide for Photocatalytic Oxidative Desulfurization of Dibenzothiophene
}

\author{
Hitam, C.N.C. ${ }^{1}$, Jalil, A.A. ${ }^{1,2^{*}}$, Triwahyono, S. ${ }^{3}$ \\ ${ }^{1}$ Department of Chemical Engineering, Faculty of Chemical and Energy Engineering, Universiti Teknologi \\ Malaysia, 81310 Johor Bahru, Johor, Malaysia \\ ${ }^{2}$ Centre of Hydrogen Energy, Institute of Future Energy, Universiti Teknologi Malaysia, 81310 Johor \\ Bahru, Johor, Malaysia \\ ${ }^{3}$ Department of Chemistry, Faculty of Science, Universiti Teknologi Malaysia, 81310 Johor Bahru, Johor, \\ Malaysia \\ *Corresponding author: aishahaj@utm.my
}

\section{Article History}

Received: March 01, 2018

Received in revised form: May 18, 2018

Accepted: June 04, 2018

Published: July 30, 2018

\begin{abstract}
Photocatalytic oxidative desulfurization (PODS) has received much attention due to low energy consumption and high efficiency, as well as simple and pollution-free operation. In this study, zinc oxide supported on titanium dioxide $\left(\mathrm{ZnO} / \mathrm{TiO}_{2}\right)$ catalysts were prepared via a simple electrochemical method. The presence of anatase phase $\mathrm{TiO}_{2}$ and wurtzite $\mathrm{ZnO}$ was confirmed by X-ray diffraction (XRD) analysis while band gap energies were determined by UV-Vis diffuse reflectance spectroscopy (UV-Vis DRS). The photocatalytic activity was tested for desulfurization of $100 \mathrm{mg} / \mathrm{L}$ dibenzothiophene (DBT). The highest desulfurization rate $\left(2.20 \times 10^{-3} \mathrm{mM} / \mathrm{min}\right)$ was achieved using $1 \mathrm{~g} / \mathrm{L}$ of $10 \mathrm{wt} \%$ $\mathrm{ZnO} / \mathrm{TiO}_{2}$ after $2 \mathrm{hr}$ under UV irradiation.
\end{abstract}

Keywords: $\mathrm{ZnO} / \mathrm{TiO}_{2}$, photocatalytic oxidative desulfurization, dibenzothiophene, electrochemical.

\subsection{INTRODUCTION}

Acid rain, global warming, atmospheric pollution, and several health effects are among crucial environmental problems that are majorly caused by the emission of sulfur oxides $\left(\mathrm{SO}_{\mathrm{x}}\right)$ produced from combustion of fuels. In order to reduce negative effects on environment and health, the acceptable sulfur level in fuel has been restricted to $10 \mathrm{mg} / \mathrm{L}$ in most developed countries and in the near future, zero-emission is accepted worldwide [1, 2]. In recent years, considerable attention has been paid to efficient desulfurization of fuel due to stringent environmental regulations [3]. A common removal process of organosulfurs in industry is called hydrodesulfurization (HDS), which is performed under high hydrogen pressure and temperature, as well as high purity of hydrogen, and this makes the process inappropriate for further reduction of sulfur content [4]. Hence, it is necessary to introduce other approaches to overcome those drawbacks, such as extractive desulfurization (EDS), adsorptive desulfurization (ADS), and biodesulfurization (BDS). Oxidative desulfurization (ODS) has become one of the most capable alternative methods than other techniques to replace HDS [5].

As one of the processes in ODS, photocatalytic oxidative desulfurization (PODS) is less harmful, has high catalytic activity, low energy consumption, and is also recyclable [6]. Heterogeneous photocatalytic removal of organic pollutant is a promising method because it can transform toxic pollutants into harmless products using mild conditions [7]. Photocatalytic reaction consists of the irradiation of a photon with the energy equal or higher than the band gap energy $\left(E_{g}\right)$ of the catalyst [8], followed by the excitation of electrons from the valence band (VB) to the largely vacant conduction band $(\mathrm{CB})$. Simultaneously, a hole $\left(\mathrm{h}^{+}\right)$with strong oxidizing ability is formed. Excited electrons $\left(\mathrm{e}^{-}\right)$are able to carry out 
reduction reactions and $\mathrm{h}^{+}$can perform oxidation reactions.

Among various types of catalysts, titanium oxide $\left(\mathrm{TiO}_{2}\right)$ has been extensively used in the photocatalytic degradation of organic pollutants due to its inexpensiveness, chemical stability, non-toxicity, and excellent photocatalytic activity [5, 9]. However, $\mathrm{TiO}_{2}$ has some drawbacks such as lower interface and easy recombination of the electron-hole pair [10]. To overcome this shortcoming, researchers have sought to improve the photoactivity of $\mathrm{TiO}_{2}$ by coupling the catalyst with other inorganic materials such as transition metals. Coupled semiconductor photocatalysts are a crucial step to enhance interfacial charge transfer to adsorbed substrates, improve the separation of electron-hole pairs, and extend the lifetime of electron-hole pairs [11].

The most capable candidate is probably zinc oxide $(\mathrm{ZnO})$ because of its low cost, wide band gap metal oxide ( $\sim 3.30 \mathrm{eV})$, and comparable photocatalytic performance to $\mathrm{TiO}_{2}$ [12]. Nowadays, coupled photocatalyst $\mathrm{ZnO} / \mathrm{TiO}_{2}$ has been studied comprehensively and the results revealed that $\mathrm{ZnO} / \mathrm{TiO}_{2}$ has superior photocatalytic performance than that of the single one. Currently, there are several studies reported on the electrochemical technique for the preparation of nanometal oxide including $\mathrm{CuO}, \alpha-\mathrm{Fe}_{2} \mathrm{O}_{3}, \mathrm{ZnO}$, and $\alpha-\mathrm{FeOOH}$ [7, 13-15]. Further loading of these oxides onto supports enhanced their properties toward consequent reactions, thus improved catalytic activity. Considering all the factors, the objectives of this study are to synthesize $\mathrm{ZnO} / \mathrm{TiO}_{2}$ and evaluate its performance in PODS.

\subsection{METHODOLOGY}

\subsection{Materials}

Dibenzothiophene (DBT), potassium peroxodisulfate, triethanolamine, sodium hydrogen carbonate, and isopropanol were provided by Merck Sdn. Bhd., Malaysia. Ammonium hydroxide $\left(\mathrm{NH}_{4} \mathrm{OH}\right)$ and acetonitrile were purchased from QRec, Malaysia. Commercial $\mathrm{TiO}_{2}\left(\mathrm{JRC}_{\mathrm{TiO}}-2\right)$ was obtained from the Catalysis Society of Japan. All of the chemicals were utilized without further purification whereas tetraethyl ammonium perchlorate (TEAP) was prepared according to a previously reported method [16].

\subsection{Synthesis of Catalysts}

In this study, $\mathrm{ZnO} / \mathrm{TiO}_{2}$ nanoparticles were synthesized by electrolysis technique using commercial $\mathrm{TiO}_{2}$ support with $\mathrm{ZnO}$ contents varied from 5-15 wt\% based on a previously reported technique [17].

\subsection{Material Characterization}

$\mathrm{X}$-ray diffraction (XRD) analysis was performed on a D8 ADVANCE Bruker X-ray diffractometer using $\mathrm{Cu}$-Ka radiation at $2 \theta=2$ to $90^{\circ}$. The Joint Committee on Powder Diffraction Standards (JCPDS) files were used to classify the phases. UV-Vis diffuse reflectance spectra (UV-Vis DRS) were recorded by a PIKE Technologies DiffusIR at room temperature in the range of wavelengths from 300 to $800 \mathrm{~nm}$ to determine the band gap energy $\left(\mathrm{E}_{\mathrm{g}}\right)$ of the catalysts.

\subsection{Photocatalytic Oxidative Desulfurization Reaction}

The photocatalytic experiment was carried out by oxidative desulfurization of model oil in a batch reactor fixed with UV lamps and a cooling system. DBT was dissolved in acetonitrile to prepare model oil with sulfur content of $100 \mathrm{mg} / \mathrm{L}$. Photocatalytic oxidative desulfurization was conducted by adding $1.0 \mathrm{~g} / \mathrm{L}$ catalysts into $50 \mathrm{~mL}$ of model oil. Under constant stirring, a solution was formed and placed in the dark for $60 \mathrm{~min}$ to achieve adsorption-desorption equilibrium. Then, the suspension was irradiated with UV lamps after an appropriate amount of hydrogen peroxide $\left(\mathrm{H}_{2} \mathrm{O}_{2}\right)$ was added into the reaction system. The next steps were similar with those reported in our previous studies $[17,18]$.

\subsection{RESULTS AND DISCUSSION}

Fig. 1 presents the XRD patterns of the catalysts. $\mathrm{Pure}^{\mathrm{TiO}}{ }_{2}$ exhibited the characteristic of anatase phase with a series of diffraction peaks at $25.4^{\circ}\left(\begin{array}{lll}1 & 0 & 1\end{array}\right), 38.5^{\circ}\left(\begin{array}{lll}1 & 1 & 2\end{array}\right), 48.2^{\circ}\left(\begin{array}{lll}2 & 0 & 0\end{array}\right), 53.9^{\circ}\left(\begin{array}{lll}1 & 0 & 5\end{array}\right)$, and 55.3 $3^{\circ}\left(\begin{array}{lll}2 & 1 & 1\end{array}\right)$ (JCPDS file no. 00-0040477) [19]. For $\mathrm{ZnO} / \mathrm{TiO}_{2}$, the anatase phase was still preserved with an additional peak of wurtzite $\mathrm{ZnO}$ at $2 \theta=31.8$, 34.5. and $36.3^{\circ}$ [14]. However, the different amount of $\mathrm{ZnO}$ loading gave a remarkable effect on the intensity of $\mathrm{TiO}_{2}$ diffraction peak. It could be seen that the peak intensity was reversely proportional to the amount of loaded $\mathrm{ZnO}$, signifying a probable structural degradation of $\mathrm{TiO}_{2}[20]$. 


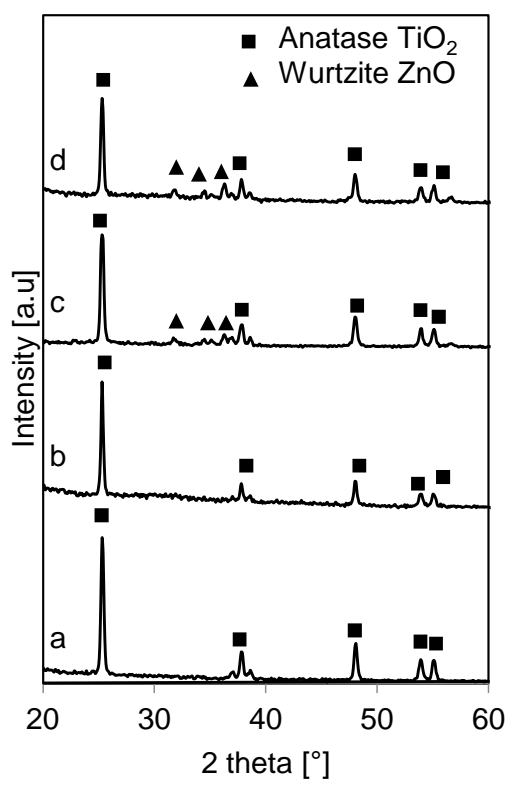

Figure 1. $\mathrm{XRD}$ patterns of (a) $\mathrm{TiO}_{2}$, (b) $5 \mathrm{wt} \% \mathrm{ZnO} / \mathrm{TiO}_{2}$, (c) $10 \mathrm{wt} \% \mathrm{ZnO} / \mathrm{TiO}_{2}$, and (d) $15 \mathrm{wt} \% \mathrm{ZnO} / \mathrm{TiO}_{2}$

The optical property of a semiconductor is known as an important factor in its photocatalytic performance, which is related to its electronic structure. Table 1 represents the direct band gap energy $\left(E_{\mathrm{g}}\right)$ of the catalysts. The values of $E_{\mathrm{g}}$ of pure $\mathrm{TiO}_{2}$ and $\mathrm{ZnO}$ were found to be 3.22 and $3.30 \mathrm{eV}$, respectively. The absorption edge of $\mathrm{TiO}_{2}$ suffered a blue shift after the incorporation of $\mathrm{ZnO}$, indicating a possible interaction between $\mathrm{TiO}_{2}$ and $\mathrm{ZnO}$ [21]. The altered light absorption of the synthesized catalysts may prevent the electron-hole pair recombination in the same light irradiation, which consequently improved photocatalytic activity [5].

Table 1. Band gap energy of catalysts

\begin{tabular}{|l|c|}
\hline Catalyst & $\begin{array}{c}\text { Band gap, } \\
(\mathbf{e V})\end{array}$ \\
\hline $\mathrm{TiO}_{2}$ & 3.22 \\
\hline $5 \mathrm{wt} \% \mathrm{ZnO} / \mathrm{TiO}_{2}$ & 3.24 \\
\hline $10 \mathrm{wt} \% \mathrm{ZnO} / \mathrm{TiO}_{2}$ & 3.26 \\
\hline $15 \mathrm{wt} \% \mathrm{ZnO} / \mathrm{TiO}_{2}$ & 3.29 \\
\hline $\mathrm{ZnO}$ & 3.30 \\
\hline
\end{tabular}

As shown in Fig. 2, the desulfurization rates of $\mathrm{ZnO} / \mathrm{TiO}_{2}$ are higher than $\mathrm{TiO}_{2}$, which might be due to the charge carrier separation by the incorporation of $\mathrm{ZnO}$. With the increasing loading of $\mathrm{ZnO}$ from 5 to $10 \mathrm{wt} \%$, the desulfurization rate increased from $1.63 \times 10^{-3}$ to $2.20 \times 10^{-3} \mathrm{mM} / \mathrm{min}$, respectively. The photocatalytic performance of $\mathrm{TiO}_{2}$ mainly depends on its effective charge carrier separation [11]. The photogenerated $\mathrm{e}^{-}$and $\mathrm{h}^{+}$can change in various ways on $\mathrm{TiO}_{2}$ surface. The most important probable steps in photocatalytic reaction are capture and recombination, which are two competitive processes. The reaction is efficient when the photogenerated electrons-holes can be captured. In the absence of proper capturers of $\mathrm{e}^{-}$or $\mathrm{h}^{+}$, the recombination step occurs and heat is emitted inside or on the surface of semiconductor. Improving the separation efficiency of the photogenerated electron-hole pairs and increasing the amount of the photogenerated activity species are the two essential ways that must be considered to enhance the photoactivity of $\mathrm{TiO}_{2}$. Previous study showed that $\mathrm{ZnO}$ is a good co-participant oxide because its energetic $\mathrm{CB}$ and VB positions are favorable redox. Additionally, it increases the lifetime of photogenerated electron-hole pairs by preventing recombination process [22]. Coupling $\mathrm{TiO}_{2}$ and $\mathrm{ZnO}$ is a beneficial way to enhance photoactivity due to their comparable band gap ( $\mathrm{ZnO} \sim 3.3$ $\mathrm{eV}, \mathrm{TiO}_{2} \sim 3.2 \mathrm{eV}$ ) and the positions of $\mathrm{CB}$ and $\mathrm{VB}$ [23]. The $\mathrm{CB}$ of $\mathrm{ZnO}$ is higher than $\mathrm{TiO}_{2}$, thus facilitates the electron transfer from $\mathrm{ZnO}$ to $\mathrm{TiO}_{2}$. Simultaneously, holes migrate from the $\mathrm{VB}$ of $\mathrm{TiO}_{2}$ to the $\mathrm{VB}$ of $\mathrm{ZnO}$ upon light irradiation. 
However, further increase of $\mathrm{ZnO}$ loading $\left(15 \mathrm{wt} \%\right.$ ) decreased the desulfurization rate to $1.79 \times 10^{-3} \mathrm{mM} / \mathrm{min}$. When excess of $\mathrm{ZnO}$ was incorporated, the active site of $\mathrm{TiO}_{2}$ might be blocked, thus influence the reaction rate.

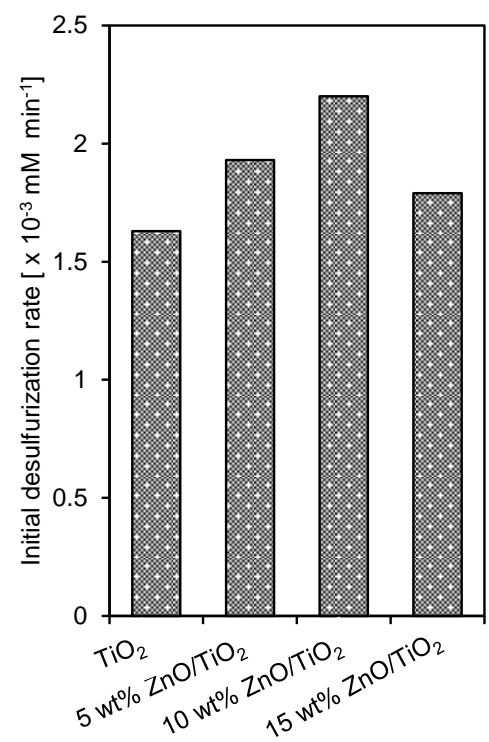

Figure 2. Catalytic performances for desulfurization of dibenzothiophene

Isopropanol (IP) slightly reduced the initial reaction rate as compared to those in the absence of a scavenger (Fig. 3), while the rate was decreased to $1.60 \times 10^{-3}$ and $1.70 \times 10^{-3} \mathrm{mM} / \mathrm{min}$ with the addition of triethanolamine (TEOA) and sodium hydrogen carbonate (SHC), respectively. Nevertheless, the photocatalytic activity was greatly inhibited using potassium peroxodisulfate (PP), signifying the noteworthy role of $\mathrm{e}^{-}$in the system. Accordingly, it is proposed that an electron-hole pair is generated in both $\mathrm{ZnO}$ and $\mathrm{TiO}_{2}$ sites upon irradiation of $\mathrm{ZnO} / \mathrm{TiO}_{2}$. The high potential and negativity of $\mathrm{e}^{-}$at the $\mathrm{CB}$ are capable to reduce $\mathrm{O}_{2}$ to enable the formation of superoxide radical $\bullet_{2}^{-}$[24]. Some of the $\mathrm{e}^{-}$at $\mathrm{CB}$ of $\mathrm{ZnO}$ might be transferred to the $\mathrm{CB}$ of $\mathrm{TiO}_{2}$. Simultaneously, $\mathrm{h}^{+}$can easily migrate from $\mathrm{VB}$ of $\mathrm{ZnO}$ to $\mathrm{TiO}_{2}$ due to the energetic $\mathrm{CB}$ and $\mathrm{VB}$ positions of $\mathrm{ZnO}$, thus preventing electron-hole recombination. The generated $\mathrm{h}^{+}$in $\mathrm{VB}$ of $\mathrm{ZnO} / \mathrm{TiO}{ }_{2}$ can thermodynamically oxidize water and hydroxyl ions to produce hydroxyl radicals $(\mathrm{OH} \bullet)^{\text {. With }}$ the presence of $\bullet \mathrm{O}_{2}{ }^{-}$ and $\mathrm{OH} \bullet$, DBT was successfully oxidized to DBT 5-oxide (DBTO) and DBT 5,5-dioxide $\left(\mathrm{DBTO}_{2}\right)$ [25].

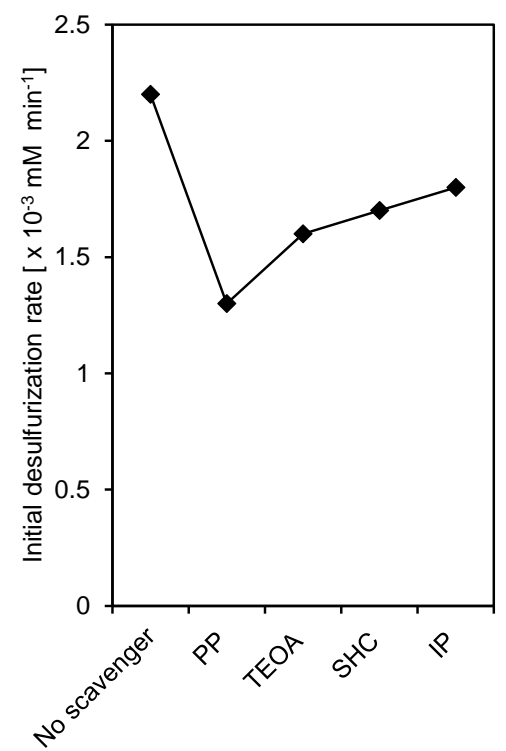

Figure 3. Desulfurization rates of dibenzothiophene in the existence of $\mathrm{e}^{-}, \mathrm{h}^{+}, \bullet \mathrm{OH}_{\mathrm{ads}}$, and $\bullet \mathrm{OH}$ scavengers 


\subsection{CONCLUSION}

In this study, $\mathrm{ZnO} / \mathrm{TiO}_{2}$ catalysts were synthesized via a simple electrochemical method. The synthesized catalysts were characterized by XRD analysis and UV-Vis DRS. The XRD results showed that pure $\mathrm{TiO}_{2}$ exhibited the characteristic of anatase phase. Similarly, $\mathrm{ZnO} / \mathrm{TiO}_{2}$ also displayed the anatase phase with an additional peak of wurtzite $\mathrm{ZnO}$. Based on UV-Vis DRS, the absorption edge of $\mathrm{TiO}_{2}$ suffered a blue shift after the incorporation of $\mathrm{ZnO}$, indicating a possible interaction between $\mathrm{TiO}_{2}$ and $\mathrm{ZnO}$. The photocatalytic activity was tested on the desulfurization of $100 \mathrm{mg} / \mathrm{L}$ of DBT. The highest desulfurization rate was obtained using $10 \mathrm{wt} \% \mathrm{ZnO} / \mathrm{TiO}_{2}$, which might be due to the electron-hole pair separation by the inclusion of $\mathrm{ZnO}$.

\section{Acknowledgements}

The authors are thankful for the financial support by the Research University Grant from Universiti Teknologi Malaysia (Grant No.12H70 and 4F423) and the award of MyPhD Scholarship (Che Ku Nor Liana Che Ku Hitam) from the Ministry of Higher Education.

\section{References}

[1] Babich, I.V. and Moulijn, J.A. 2003. Science and technology of novel processes for deep desulfurization of oil refinery streams: a review, Fuel 82: 607-631.

[2] Srivastava, V.C. 2012. An evaluation of desulfurization technologies for sulfur removal from liquid fuels, RSC 2: 759-783.

[3] Triantafyllidis, K.S. and Deliyanni, E.A. 2014. Desulfurization of diesel fuels: Adsorption of 4,6 DMDBT on different origin and surface chemistry nanoporous activated carbons. Chemical Engineering Journal. 236: 406-414.

[4] Gao, X., Fu, F., Zhang, L., Li, W. 2013. The preparation of Ag-BiVO metal composite oxides and its application in efficient photocatalytic oxidative thiophene. Physica B 419: 80-85.

[5] Wang, C., Zhu, W., Xu, H., Zhang, M., Chao, Y., Yin, S., Li, H., Wang, J. 2014. Preparation of TiO $\mathrm{T}_{2} / \mathrm{g}^{-} \mathrm{C}_{3} \mathrm{~N}_{4}$ composites and their application in photocatalytic oxidative desulfurization. Ceramic International. 40: 11627-11635.

[6] Zhu, W., Li, Y., Dai, B., Xu, H., Wang, C., Chao, Y., Liu, H. 2013. Photocatalytic oxidative desulfurization of dibenzothiophene catalyzed by amorphous $\mathrm{TiO}_{2}$ in ionic liquid. Korean Journal of Chemical Engineering: 1-7.

[7] Jalil, A.A., Satar, M.A.H., Triwahyono, S., Setiabudi, H.D., Kamarudin, N.H.N., Jaafar, N.F., Sapawe, N., Ahamad, R. 2013. Tailoring the current density to enhance photocatalytic activity of $\mathrm{CuO} / \mathrm{HY}$ for decolorization of malachite green. Journal of Electroanalytical Chemistry. 701: 50-58

[8] Pekárek, S., Mikeš, J., Krýsa, J. 2015. Comparative study of $\mathrm{TiO}_{2}$ and $\mathrm{ZnO}$ photocatalysts for the enhancement of ozone generation by surface dielectric barrier discharge in air. Applied Catalysis A: General 502: 122-128.

[9] Li, F., Liu, Y., Sun, Z., Zhao, Y., Liu, R., Chen, L., Zhao, D. 2012. Photocatalytic oxidative desulfurization of dibenzothiophene under simulated sunlight irradiation with mixed-phase $\mathrm{Fe}_{2} \mathrm{O}_{3}$ prepared by solution combustion. Catalysis Science and Technology. 2: $1455-1462$.

[10] Jaafar, N. F., Jalil, A. A., Triwahyono, S., Shamsuddin, N. 2015. New insights into self-modification of mesoporous titania nanoparticles for enhanced photoactivity: effect of microwave power density on formation of oxygen vacancies and $\mathrm{Ti}^{3+}$ defects. RSC Advances. 5: 90991 .

[11] Shifu, C., Wei, Z., Wei, L., Sujuan, Z. 2008. Preparation, characterization and activity evaluation of p-n junction photocatalyst p-ZnO/n-TiO ${ }_{2}$. Applied Surface Science. 255: 2478-2484.

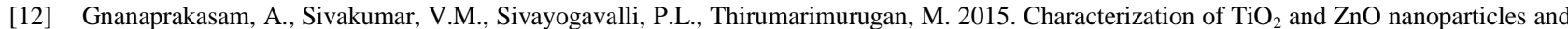
their applications in photocatalytic degradation of azodyes. Ecotoxicology and Environmental Safety 121: 121-125.

[13] Jaafar, N.F., Jalil, A.A., Triwahyono, S., Muhid, M.N.M., Sapawe, N., Satar, M.A.H., Asaari, H. 2012. Photodecolorization of methyl orange over $\alpha-\mathrm{Fe}_{2} \mathrm{O}_{3}$-supported HY catalysts: The effects of catalyst preparation and dealumination. Chemical Engineering Journal. 191 : $112-122$.

[14] Jusoh, N.W.C., Jalil, A.A., Triwahyono, S., Setiabudi, H.D., Sapawe, N., Satar, M.A.H., Karim, A.H., Kamarudin, N.H.N., Jusoh, R., Jaafar, N.F., Salamun, N., Efendi, J. 2013. Sequential desilication-isomorphous substitution route to prepare mesostructured silica nanoparticles loaded with $\mathrm{ZnO}$ and their photocatalytic activity. Applied Catalysis A: General. 468: 276- 287.

[15] Jusoh, R., Jalil, A.A., Triwahyono, S., Idris, A., Haron, S., Sapawe, N., Jaafar, N.F., Jusoh, N.W.C. 2014. Synthesis of reverse micelle $\alpha$-FeOOH nanoparticles in ionic liquid as an only electrolyte: Inhibition of electron-hole pair recombination for efficient photoactivity. Applied Catalysis A: General. 469: 33. 
[16] Jalil, A.A., Kurono,N., Tokuda,M.2002. Facile synthesis of ethyl 2-arylpropenoates by cross-coupling reaction using electrogenerated highly reactive zinc. Tetrahedron. 58: 7477-7484.

[17] Hitam, C.N.C., Jalil, A.A., Triwahyono, S., Rahman, A.F.A., Hassan, N.S., Khusnun, N.F., Jamian, S.F., Mamat, C.R., Nabgan, W., Ahmad, A. 2018. Effect of carbon-interaction on structure-photoactivity of $\mathrm{Cu}$ doped amorphous $\mathrm{TiO}_{2}$ catalysts for visible-light-oriented oxidative desulphurization of dibenzothiophene. Fuel. 216: 407-417.

[18] Hitam, C. N. C., Jalil, A. A., Triwahyono, S., Ahmad, A., Jaafar, N. F., Salamun, N., Fatah, N. A. A., Teh, L. P., Khusnun, N. F., and Ghazali, Z. 2016. Synergistic interactions of $\mathrm{Cu}$ and $\mathrm{N}$ on surface altered amorphous $\mathrm{TiO}_{2}$ nanoparticles for enhanced photocatalytic oxidative desulfurization of dibenzothiophene. RSC Advances. 6:76259-76268.

[19] Jaafar, N.F., Jalil, A.A., Triwahyono, S., Efendi, J., Mukti, R.R., Jusoh, R., Jusoh, N.W.C., Karim, A.H., Salleh, N.F.M., Suendo, V. 2015. Direct in situ activation of $\mathrm{Ag}^{0}$ nanoparticles in synthesis of $\mathrm{Ag} / \mathrm{TiO}_{2}$ and its photoactivity. Applied Surface Science. 338: 75-84.

[20] Aziz, M.A.A., Jalil, A.A., Triwahyono, S., Saad, M.W.A. 2015. $\mathrm{CO}_{2}$ methanation over Ni-promoted mesostructured silica nanoparticles: Influence of Ni loading and water vapor on activity and response surface methodology studies. Chemical Engineering Journal 260: 757-764.

[21] Aazam, E.S. 2014. Visible light photocatalytic degradation of thiophene using $\mathrm{Ag}-\mathrm{TiO}_{2} /$ multi-walled carbon nanotubes nanocomposite. Ceramics International 40: 6705-6711.

[22] Pérez-Larios, A., Lopez, R., Hernández-Gordillo, A., Tzompantzi, F., Gómez, R., Torres-Guerra, L.M. 2012. Improved hydrogen production from water splitting using $\mathrm{TiO}_{2}-\mathrm{ZnO}$ mixed oxides photocatalysts. Fuel 100: 139-143.

[23] Todorova, N., Giannakopoulou, T., Pomoni, K., Yu, J., Vaimakis, T., Trapalis, C. 2015. Photocatalytic $\mathrm{NO}_{\mathrm{x}}$ oxidation over modified $\mathrm{ZnO} / \mathrm{TiO}{ }_{2}$ thin films. Catalysis Today. 252: 41-46.

[24] Jusoh, N.W.C., Jalil, A.A., Triwahyono, S., Karim, A.H., Salleh, N.F.,Annuar, N.H.R., Jaafar, N.F., Firmansyah, M.L., Mukti, R.R., Ali, M.W 2015. Structural rearrangement of mesostructured silica nanoparticles incorporated with $\mathrm{ZnO}$ catalyst and its photoactivity: Effect of alkaline aqueous electrolyte concentration. Applied Surface Science 330: 10-19.

[25] Juan, Z., Dishun, Z., Liyan, Y., Yongbo, L. 2010. Photocatalytic oxidation dibenzothiophene using TS-1. Chemical Engineering Journal 156: $528-531$. 